\title{
PHOTOELECTRIC PHOTOMETRY OF COMET KOHOUTEK (1973f)
}

\section{Lubos Kohoutek}

1 Introduction

Comet Kohoutek (1973f) has been observed with the $50 \mathrm{~cm}$ (f/15) reflecting telescope of the European Southern Observatory, La Silla, Chile, on fourteen nights between January 16 and 30, when the heliocentric and geocentric distances of the comet were $r=0 \quad 66$ - $100 \mathrm{~A}$.U and $\Delta=081-0.96 \mathrm{~A}$. U, respectively The $40^{\prime \prime}$ and $80^{\prime \prime}$ diaphragms were used for the photometry of the cometary head (EMI 6256 A photomultiplier) in the UBV system and with six interference filters: $\mathrm{CN} 3884 \AA, \mathrm{CO}^{+} 4267 \AA, \mathrm{C}_{2} 4737 \AA, \mathrm{C}_{2} 5172 \AA$, cont. $5300 \AA$ and Na $5893 \AA$.

The atmospheric conditions were good but the accuracy of our observations was lower than usual due to large extinction (air mass 25 to 43 ) and twilight. The mean error of one measurement of $\log \mathrm{F}$ in all but $\mathrm{Na} 5893 \AA$ filters can be estimated at +0.02 , whereas the accuracy through the $\mathrm{Na}$ filter was substantially lower

\section{UBV Observations}

Observations in UBV system are given in Table 1 ( $N$ - number of measurements in the respective night) They are also presented in Fig 1, but reduced to the distance of $\Delta=1 \mathrm{~A}$. U and corrected to standard circular area of $\mathrm{D}\left(40^{\prime \prime}\right)=290 \times 10^{4} \mathrm{~km}$ and $\mathrm{D}\left(80^{\prime \prime}\right)=$ $5.80 \times 10^{4} \mathrm{~km}$ in diameter, respectively, centered on the cometary nucleus. The above areas correspond to those seen in the diaphragms of $40^{\prime \prime}$ and $80^{\prime \prime}$ and from the distance $1 \mathrm{~A}$. U For that correction the mean intensity gradients in the coma were applied as deduced from the measurements in both diaphragms. 


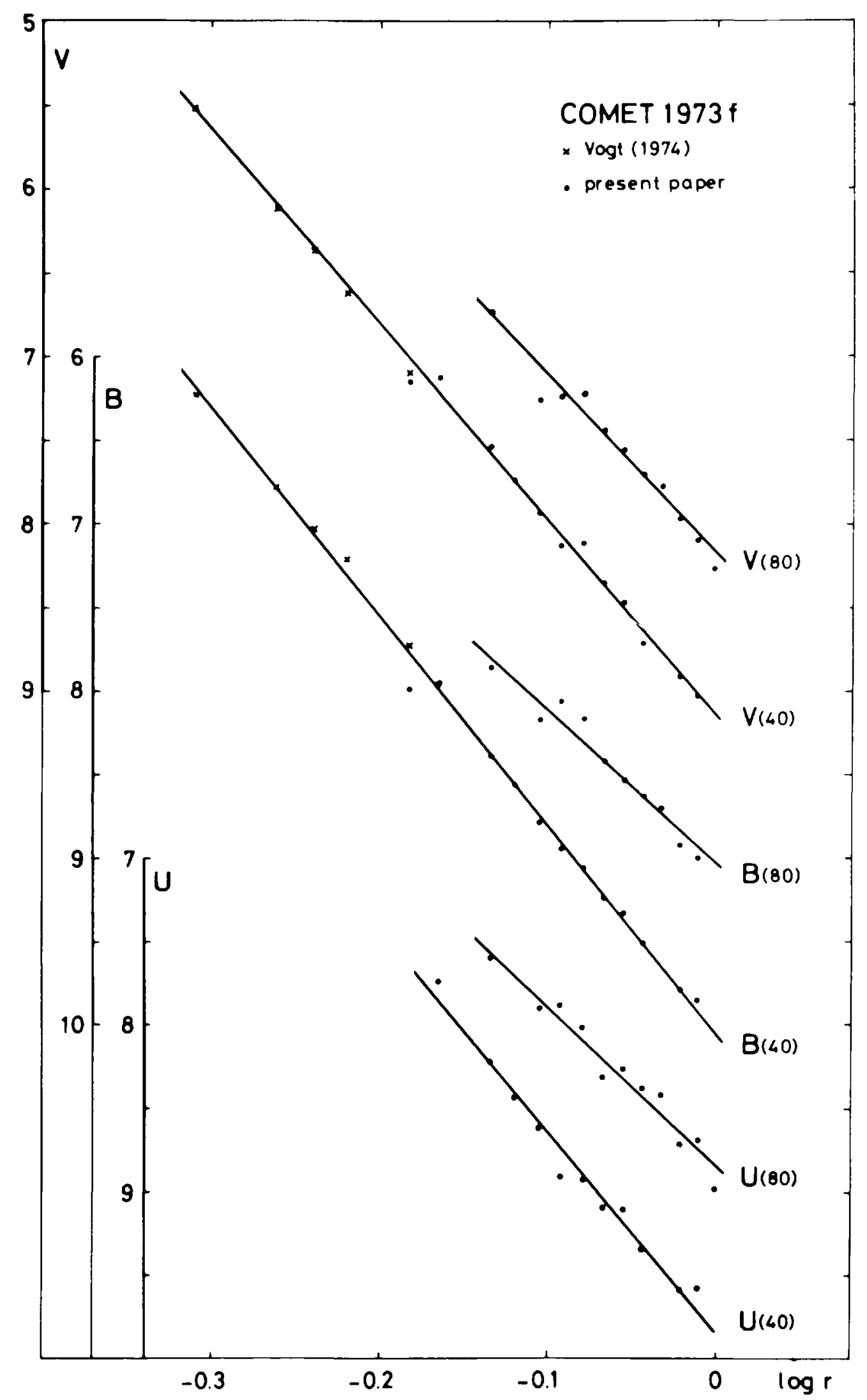

Fig. 1 The reduced brightness of Comet $1973 f$ in UBV system [ $\Delta=1$ A.U. ; standard circular area of $290 \times 10^{4} \mathrm{~km}(40)$ and $5.80 \times 10^{4} \mathrm{~km}(80)$ in diameter] as a function of $\log \mathrm{r}$. 


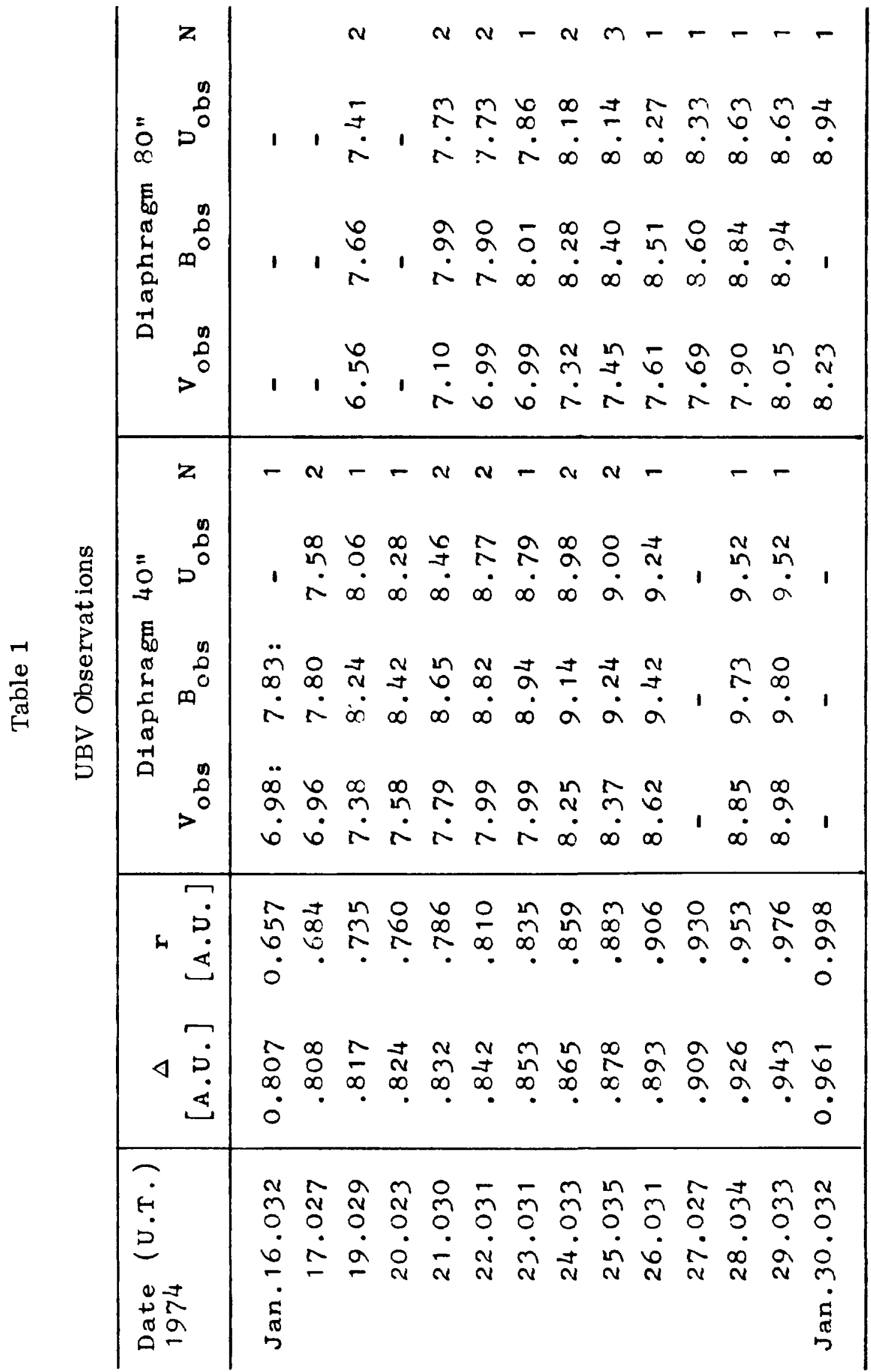


In order to increase the time interval of observation we used the photoelectric measurements which were made by Vogt (1974) at La Silla under similar conditions. The $B$ and $V$ magnitudes in the diaphragms of $29^{\prime \prime}$ and $45^{\prime \prime}$, respectively, we re also corrected to standard circular area of $40^{\prime \prime}(\Delta=1$ A. U. $)$.

The absolute magnitudes, $m_{o}$, and the photometric exponents, $n$, derived from the well-known formula

$$
m_{1}=m_{0}+2.5 n \log r
$$

are given in Table 2 togethe $r$ with the respective interval of $\log r$. The absolute colour indices in the $40^{\prime \prime}$ and $80^{\prime \prime}$ diaphragms differ from each other only slightly and within the observing errors:

$$
\begin{aligned}
& (\mathrm{B}-\mathrm{V})_{\mathrm{O},\left(40^{\prime \prime}\right)}=0.90,(\mathrm{U}-\mathrm{B})_{\mathrm{O},\left(40^{\prime \prime}\right)}=-0.20 ;(\mathrm{B}-\mathrm{V})_{\mathrm{O},\left(80^{\prime \prime}\right)}=0.86, \\
& (\mathrm{U}-\mathrm{B})_{\mathrm{O},\left(80^{\prime \prime}\right)}=-0.19 .
\end{aligned}
$$

The comet's brightness has been diminishing rather quickly after the perihelion passage, in fact more rapidly in the inner part of the head ( $n$ between 4.6 and 5.0) than in the outer part ( $n$ between 3.6 and 4.2). When extrapolating the best determined straight lines of $V\left(40^{\prime \prime}\right)$ and $\mathrm{B}\left(40^{\prime \prime}\right)$ back to the perihelion, $\mathrm{V}_{\max }\left(40^{\prime \prime}\right) \sim-0.7$ and $\mathrm{B}_{\max }\left(40^{\prime \prime}\right)$ $\sim-0.5$ can be obtained.

Assuming a density law $d(\rho) \sim \rho^{-2}(\rho$ is the distance from the nucleus) for the emitting molecules and dust particles in the spherically symmetrical head, an intensity law $I(\rho) \sim \rho^{-1}$ can be derived, which leads to the magnitude difference $\Delta \mathrm{m}=\mathrm{m}\left(40^{\prime \prime}\right)$ $m\left(80^{\prime \prime}\right)=0.75$ for the diaphragms used. Our observations show $\Delta \mathrm{m}>0.75$ and continuously growing with time. The mean values are: $\Delta \mathrm{m}_{\mathrm{V}}=0.904, \Delta \mathrm{m}_{\mathrm{B}}=0.817, \Delta \mathrm{m}_{\mathrm{U}}=0.853$. The difference between the observed and theoretical $\Delta$ m-values reflects the deviation from the $\rho^{-1}$ law and can be expressed by $\rho^{-\mathcal{H}}$; obviously 


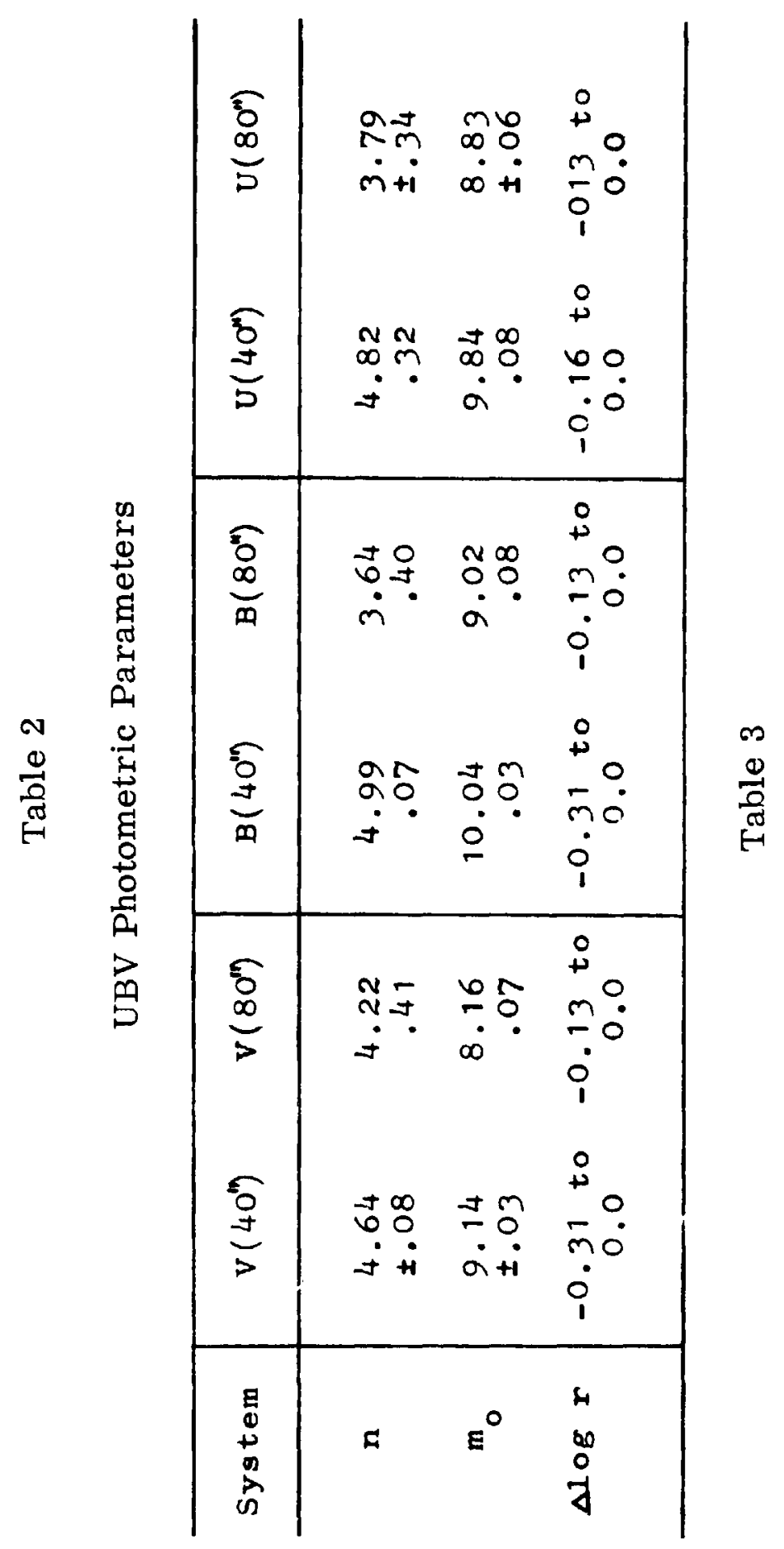

\begin{tabular}{|c|c|c|c|}
\hline$\underset{\substack{\alpha \\
\alpha}}{a=}$ & $\frac{r}{a}$ & in & n \\
\hline 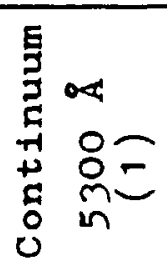 & $\begin{array}{l}0 \\
0 \\
\text { in }\end{array}$ & $r$ & in \\
\hline 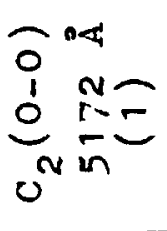 & $\frac{\infty}{\frac{\infty}{n}}$ & $\stackrel{\infty}{r}$ & 光 \\
\hline 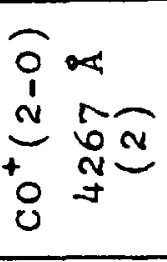 & \begin{tabular}{l} 
In \\
$\stackrel{0}{ }$ \\
\multirow{J}{*}{}
\end{tabular} & $\hat{\sigma}$ & $\stackrel{m}{\sim}$ \\
\hline 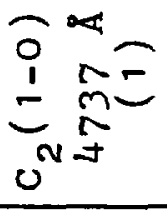 & 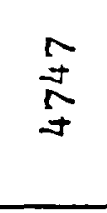 & $\begin{array}{l}\infty \\
\text { in }\end{array}$ & N \\
\hline 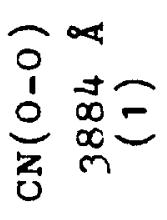 & $\begin{array}{l}N \\
\alpha \\
\infty \\
\end{array}$ & $\stackrel{N}{\exists}$ & $\vec{R}$ \\
\hline $\begin{array}{l}4 \\
0 \\
+ \\
-1 \\
-1 \\
\text { A }\end{array}$ & 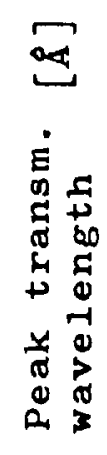 & 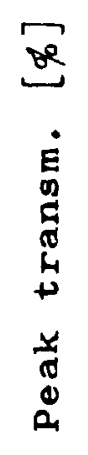 & 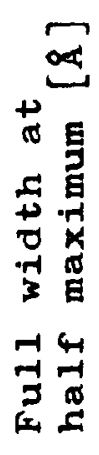 \\
\hline
\end{tabular}




$$
\mathcal{H}=2-\frac{2 \Delta m}{5 \log \left(\mathrm{D}_{2} / \mathrm{D}_{1}\right)}
$$

where $\mathrm{D}_{2}, \mathrm{D}_{1}$ are the respective diameters of the diaphragms. Physically it reflects (a) the production of visible radicals from parent molecules in this part of the inner coma, (b) the deviation from the regular ejection of particles from the nucleus and/or (c) the dissociation of the molecules by sunlight. This last effect can probably be neglected due to the large trajectory of molecules before dissociation compared with the size of the diaphragms used. According to (2) we have: $\mathscr{H}_{\mathrm{V}}=0.80, \mathscr{K}_{\mathrm{B}}=091, \mathscr{K}_{\mathrm{U}}=087$

\section{Observations through Interference Filters}

The luminosities of the cometary head in the $40^{\prime \prime}$ and $80^{\prime \prime}$ diaphragms and through the interference filters (see Table 3) were measured using the comparison star $\eta$ Hya, for which Hayes (1970) has published the energy distribution. We adopted the $\mathrm{V}$ magnitude of $\eta$ Hya to be 4289 (Blanco et al., 1968 - mean value), the V magnitude of the Sun -26.74 (Allen, 1973), and the flux from a star of zero visual magnitude outside the atmosphere to be $3.73 \times 10^{-6}$ erg. $\mathrm{cm}^{-2} \cdot \mathrm{s}^{-1}$ in the $\mathrm{V}$ region (Allen, 1973) The observed fluxes, $\mathrm{F}_{\text {obs }}$, are given in Table 4 for $\mathrm{CN} 3884 \AA, \mathrm{C}_{2} 4737 \AA$ and $5172 \AA$, and continuum at $5300 \AA$.

Analogically to UBV data, the differences $\Delta \mathrm{m}=\mathrm{m}\left(40^{\prime \prime}\right)-\mathrm{m}\left(80^{\prime \prime}\right)$ for molecules $\mathrm{CN}, \mathrm{C}_{2}$ as well as for dust in the continuum were found to be larger than expected according to the simple intensity law, and increasing with time. We found the following mean values: $\mathscr{H}_{\mathrm{CN}}=075, \quad \mathcal{K}_{\mathrm{C}_{2}}=077$, and $\mathscr{H}_{5300}=090$ The $\mathscr{H}_{5300}<1$ can be explained by the diminishing ejection of dust particles from the nucleus. Probably both effects (a) and (b) are responsible for ${ }^{\mathcal{H}} \mathrm{CN}, \mathrm{C}_{2} \gg 1$ 


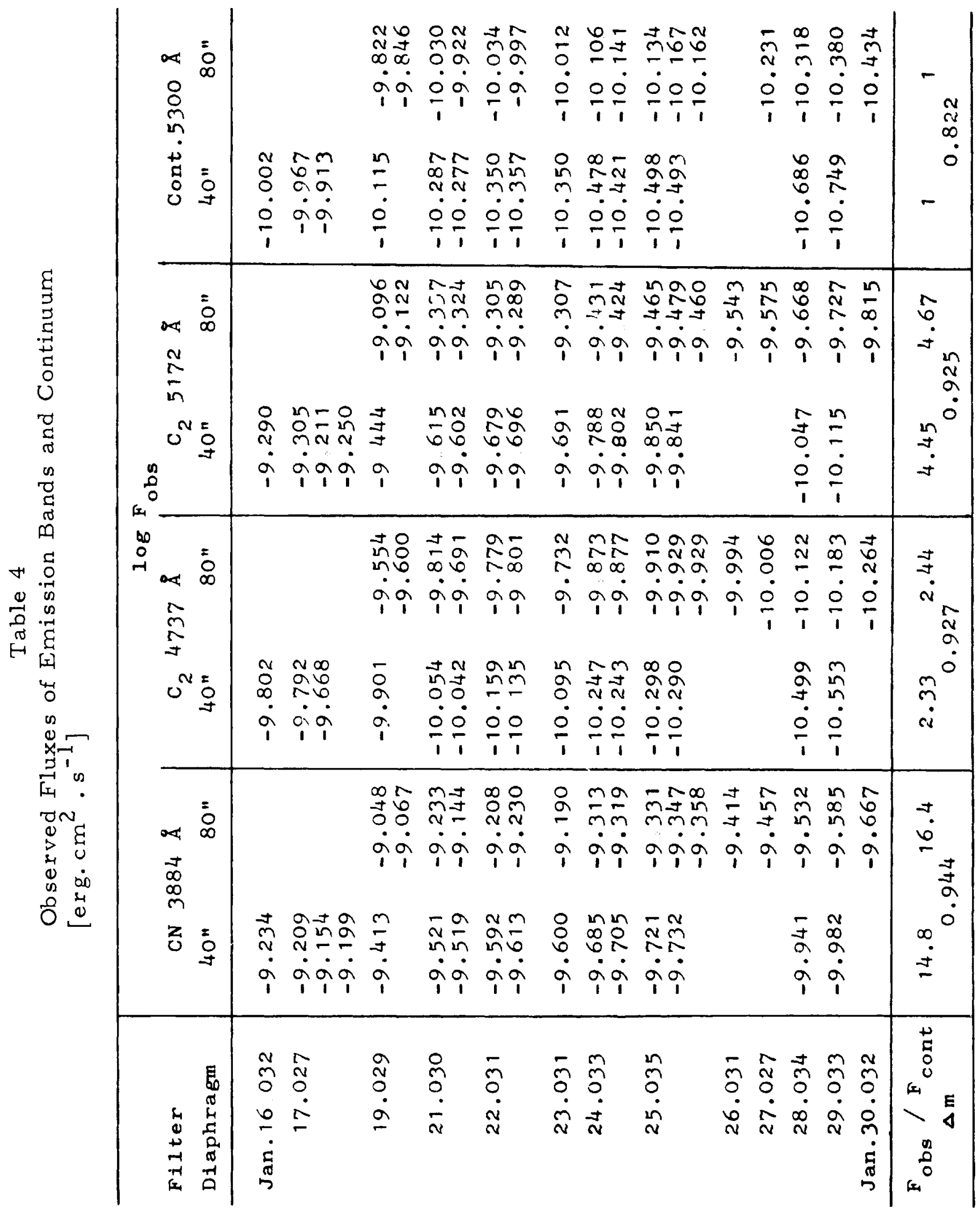


The energy distribution of the cometary continuum has been assumed to be of solar type Then, the contribution of such a cometary continuum in the five interference filters could be calculated from the continuum measured in $5300 \AA$. The ratio of the observed total flux and the calculated continuum flux in the respective filter combination is also given in Table 4 . We find that about 95 per cent of the radiation transmitted by the $\mathrm{CN} 3884 \AA$ filter is the emission contribution and that the fraction of emissions by the $C_{2} 4737 \AA$ and $5172 \AA$ filters are 58 and 78 per cent, respectively On the other hand, the observed total flux in the $\mathrm{CO}^{+} 4267 \AA$ filter is only about 4 per cent larger than that of the continuum Our. slit spectra of January 6 to 14 show either a missing or only very faint $\mathrm{CO}^{+}$ emission, so that the radiation transmitted by this filter should originate entirely from the cometary continuum. This fact supports strongly our assumption about the energy distribution of the cometary continuum.

Our measurements in the Na $5893 \AA$ filter require special care The sodium doublet was very strong on the slit spectra between January 5 and 8 ( $r=033$ to $0.42 \mathrm{~A}$. U ) and its brightness has diminished till January 12 ( $\mathrm{r}=054 \mathrm{~A}$. U ) (Kohoutek, Rahe, 1974) The emission contribution in this filter was still about 75 per cent of the total observed flux on January $16\left(\mathrm{r}=0.66 \mathrm{~A}\right.$ 。 $\left.\mathrm{U}_{\circ}\right)$, but only about 18 per cent on January $17(\mathrm{r}=0.68 \mathrm{~A}$. U ) After January 19 the emissions contributed only with 14 per cent assuming that the cometary continuum was of the solar type If the natrium doublet was totally absent in $\mathrm{r} \Xi 0.7 \mathrm{~A}$. U, the measurements in the Na $5893 \AA$ filter would represent a colour excess of $+0^{\mathrm{m}} 16$ in the continuum, possibly caused by the scattering in the cometary head. Unfortunately, due to the very low quantum efficiency of the photomultiplier in that wavelength, the measuring errors were large 
and the above result seems to be very uncertain. For that reason our assumption that the cometary continuum is of the pure reflection type has not been changed.

The observations through the interference filters were treated in the same way as in case of UBV data. The observed fluxes were reduced to $\Delta=1 \mathrm{~A}$. $\mathrm{U}$ and corrected to standard linear area in the cometary head, $\mathrm{D}\left(40^{\prime \prime}\right)$ and $\mathrm{D}\left(80^{\prime \prime}\right)$ First of all, the important ratio of the absolute brightness of the dust and of the gas coma, $\mathrm{k}=$ $\mathrm{F}_{\mathrm{o}, \mathrm{d}} / \mathrm{F}_{\mathrm{O}, \mathrm{g}}$, could be estimated. Assuming, that the effective band width in the $U, B, V$ is $680 \AA, 980 \AA$ and $890 \AA$, respectively (Allen, 1973), we calculated the contribution of the cometary continuum to the total brightness in the respective colours. Putting $F_{o, \text { cont }}=F_{o, d}$ and $F_{o}(i)=F_{o, g}+F_{o, d}$, where $F_{o}(i)$ is the corrected flux energy in the $i=V, B, U$ colour transformed from the absolute magnitude (see Table 2), we received the following. results:

$$
\begin{aligned}
& \mathrm{k}_{\mathrm{V}}\left(40^{\prime \prime}\right)=0.69 \quad \mathrm{k}_{\mathrm{V}}\left(80^{\prime \prime}\right)=066 \\
& \mathrm{k}_{B}\left(40^{\prime \prime}\right)=106 \quad \mathrm{k}_{\mathrm{B}}\left(80^{\prime \prime}\right)=0 \quad 84 \\
& \mathrm{k}_{U}\left(40^{\prime \prime}\right)=0.61 \quad \mathrm{k}_{\left.U^{\left(80^{\prime \prime}\right.}\right)=0} 56 \text {. }
\end{aligned}
$$

The dust coma is more concentrated toward the nucleus than the cometary gas. Besides, the increase of $\mathrm{k}$ with time in the interval between $\mathrm{r} \quad 0 \quad 6$ and $10 \mathrm{~A}$. $\mathrm{U}$ was found in all colours.

In order to know the fluxes of the emission bands, the fraction of their total radiation, that was passing through the respective filter, has to be determined. Besides, the contribution of other emissions in the filter was estimated, giving 73 per cent in the CN $3884 \AA$ 
filter, 26 per cent in the $\mathrm{C}_{2} 4737 \AA$ filter and 11 per cent in the $\mathrm{C}_{2} 5172 \AA$ filter from the total emission flux. The corrected fluxes of the emission bands $\mathrm{CN}(0-0) \Delta \mathrm{v}=0, \mathrm{C}_{2}(1-0) \Delta \mathrm{v}=+1$, and $C_{2}(0-0) \Delta v=0$, respectively, are plotted versus $\log r$ on Figs 2, 3 and 4 and compared with the total flux measured in the continuum $5300 \AA$ (Fig. 5) The equivalent width of the $5300 \AA$ filter was $46 \AA$

In the first approximation there is a linear dependence of $\log \mathrm{F}$ on $\log \mathrm{r}$ in both $40^{\prime \prime}$ and $80^{\prime \prime}$ circular areas for the emission bands as well as for the continuum The slopes, $n$, and the absolute brightnesses ( $\Delta=r=1$ A. U. ), $\log F_{o}$, in the relation

$$
\log F^{\prime}=\log F_{0}-n \log r
$$

are given in Table 5. The interval of $\log r$ was -018 to -001 in the $40^{\prime \prime}$ area and -013 to 00 in the $80^{\prime \prime}$ area

For continuum at $5300 \AA$ the following parameters were found: $\mathrm{n}\left(40^{\prime \prime}\right)=451, \log \mathrm{F}_{\mathrm{O}}\left(40^{\prime \prime}\right)=-10806 ; \mathrm{n}\left(80^{\prime \prime}\right)=381, \log \mathrm{F}_{\mathrm{O}}\left(80^{\prime \prime}\right)=$ -10.424 .

The photometric exponents, $\mathrm{n}$, lie for the emission bands as well as for the continuum in the same range as in case of the UBV data (see Table 2) Also $\mathrm{n}\left(40^{\prime \prime}\right)>\mathrm{n}\left(80^{\prime \prime}\right)$ can be stated with the exception of the $\mathrm{C}_{2}(1-0)$ band probably because of larger observing errors.

4 Desorption Heats and Number of $\mathrm{CN}$ and $\mathrm{C}_{2}$ Molecules

Using Levin's theory (1943) we may express the logarithm intensity of the gas constituent of the coma by 


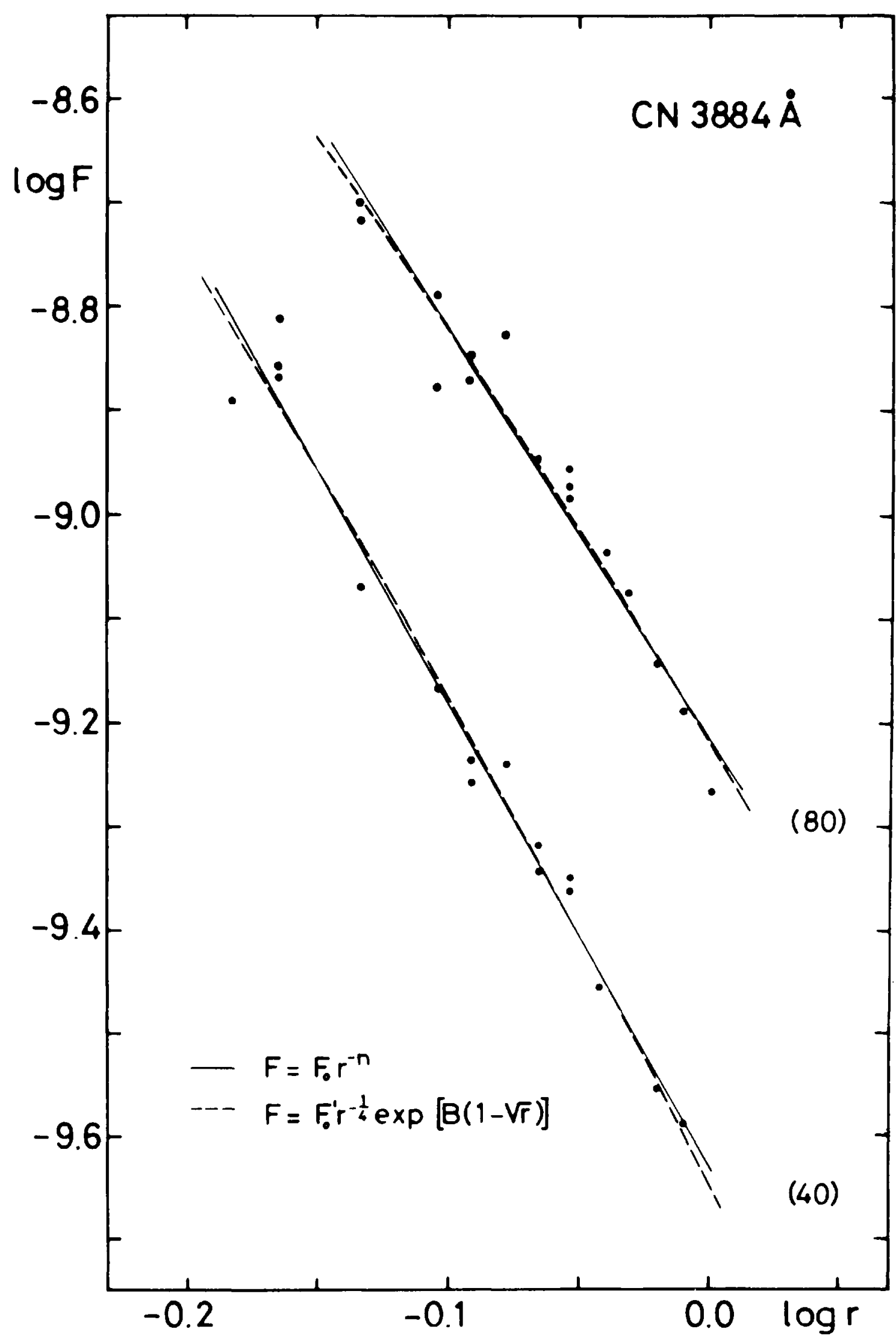

Fig. 2 The reduced flux of the $\mathrm{CN}(0-0) 3884 \AA$ emission band as a function of heliocentric distance. See the text. 


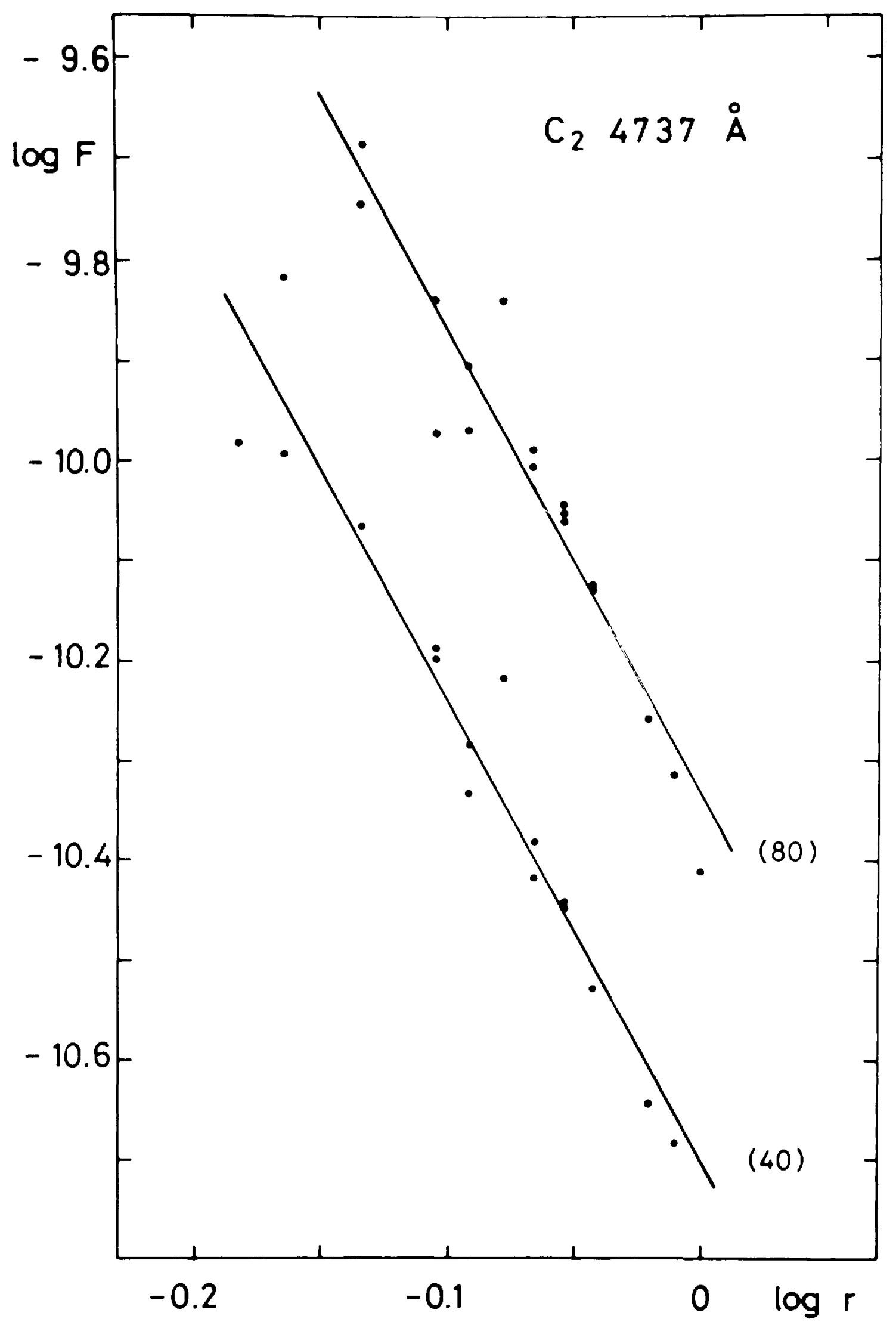

Fig. 3 The reduced flux of the $\mathrm{C}_{2}(1-0) 4737 \AA$ emission band as a function of heliocentric distance see the text. 


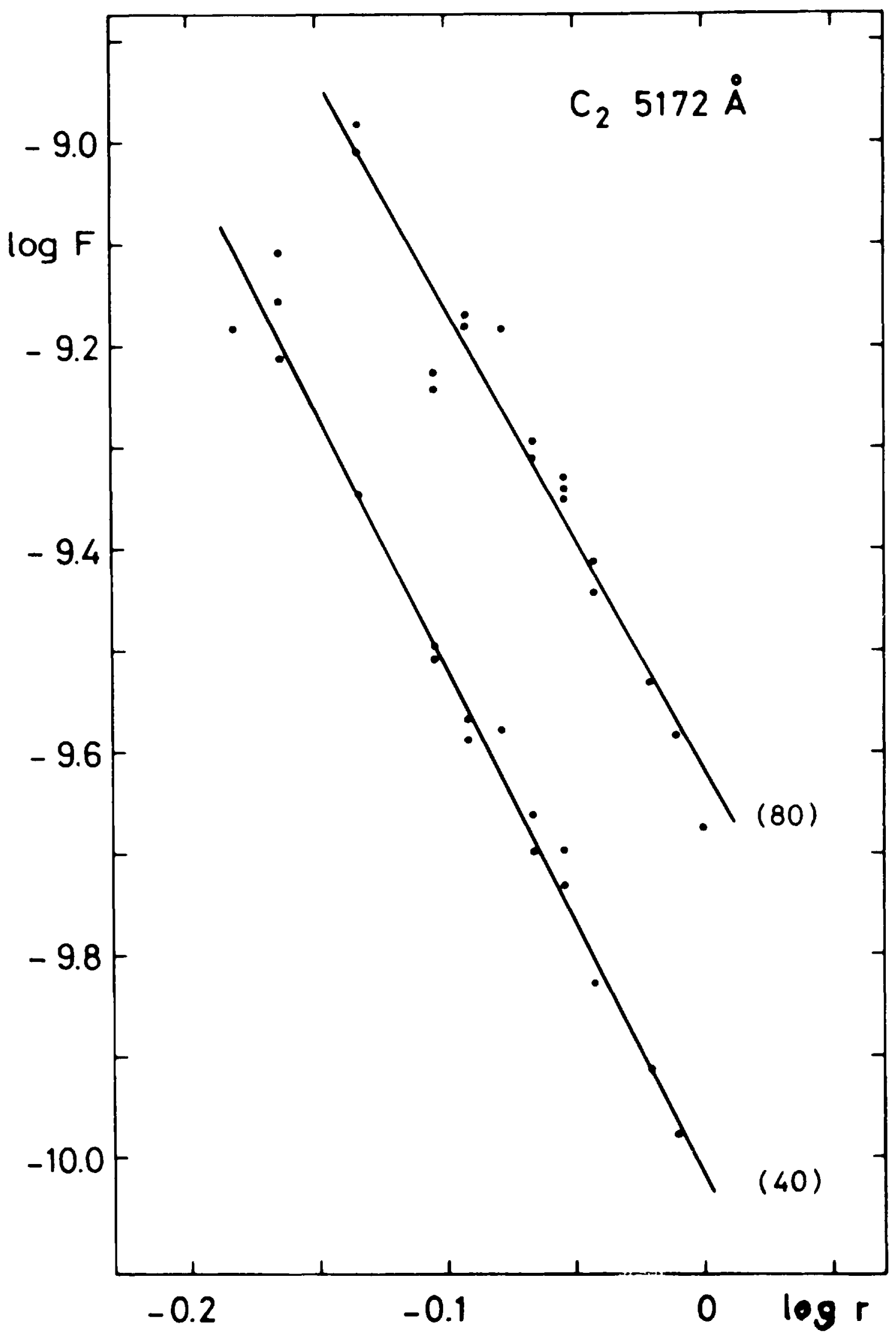

Fig. 4 The reduced flux of the $\mathrm{C}_{2}(0-0) 5172 \AA$ emission band as a function of heliocentric distance. See the text. 


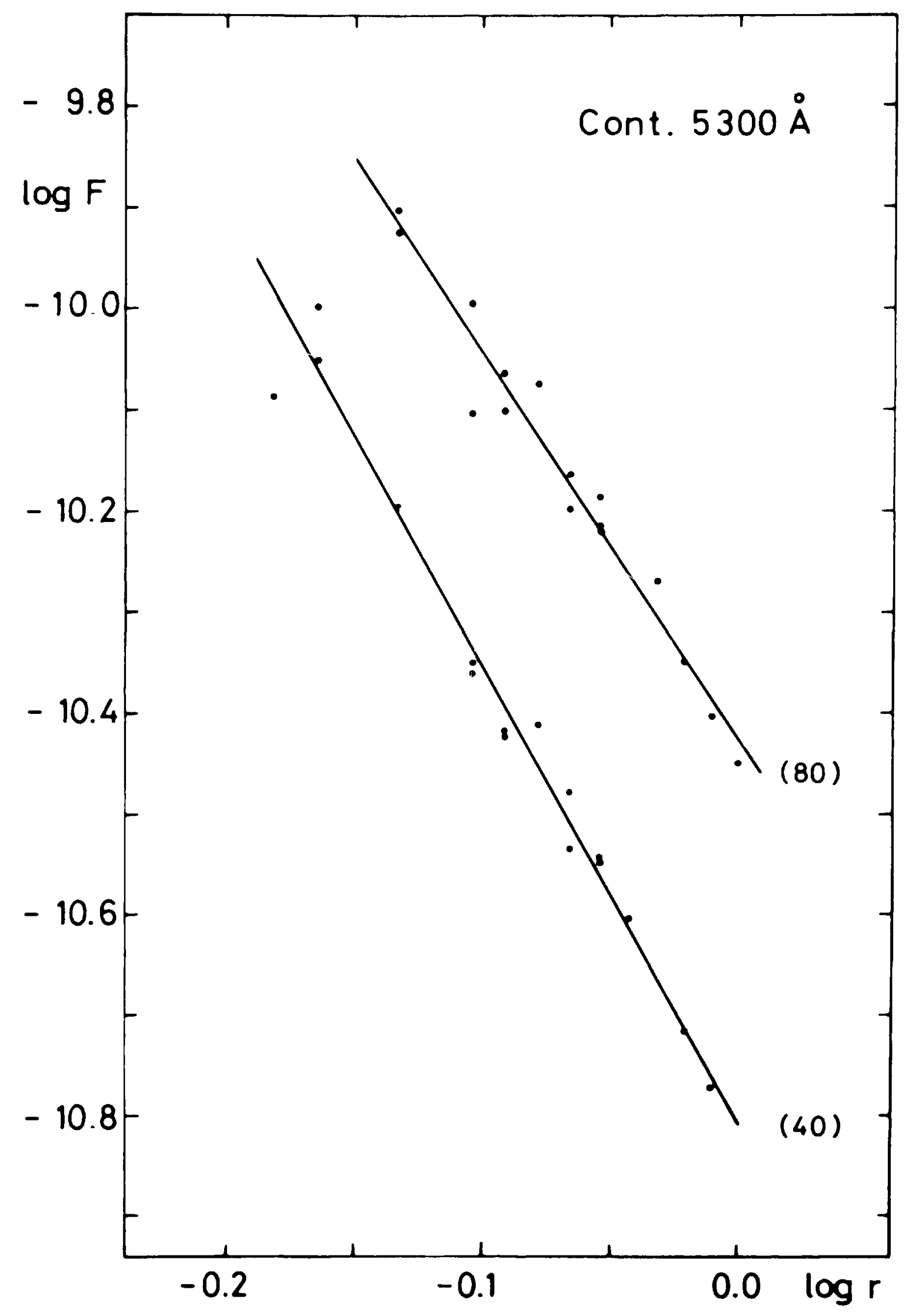

Fig. 5 The reduced flux in the continuum at $5300 \AA$ as a function of heliocentric distance. The eifective band width is $46 \AA$. 


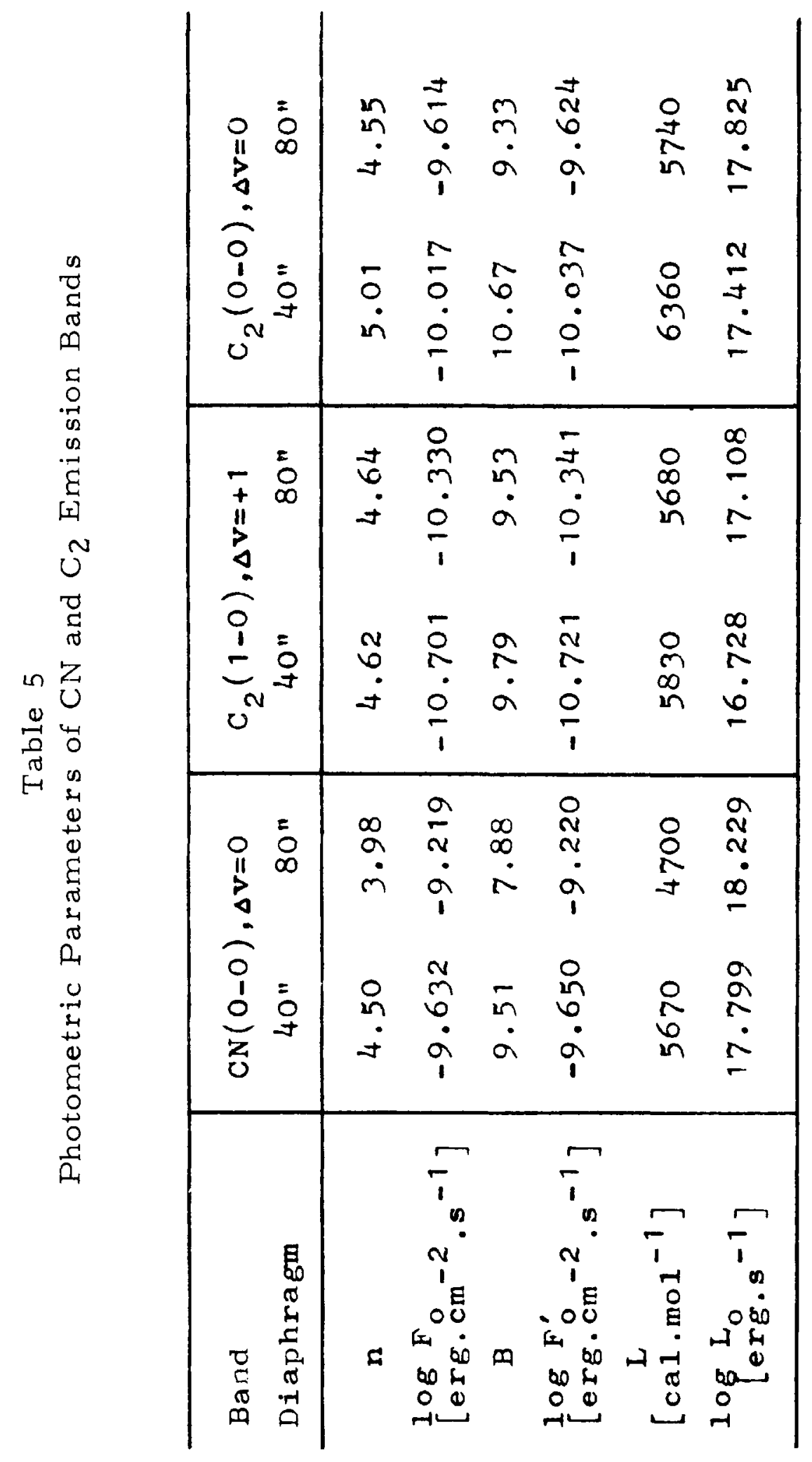




$$
\log F=\log F_{o}^{\prime}-\frac{\alpha}{2} \log r+B\left(1-r^{\alpha}\right) \log e
$$

where $B=L / R T_{O}, L$ - desorption or evaporation heat, $R$ - gas constant, $\mathrm{T}_{\mathrm{O}}$ - temperature of the nucleus at a distance of $1 \mathrm{~A} . \mathrm{U}$ The constant $\alpha$ in the relation $T=T_{0} \quad r^{-\alpha}$ corresponds to 05 if the nucleus is in a thermal equilibrium state. The constants B and $\log \mathrm{F}_{\mathrm{o}}^{\prime}$ for the $\mathrm{CN}$ and $\mathrm{C}_{2}$ emission bands are also given in Table 5 (for $\alpha=0$ 5) Both relations, (1a) and (3) differ only very slightly from each other as shown in the example of Fig. 2 The desorption heat $\mathrm{J}_{1}\left[\mathrm{cal} . \mathrm{mol}^{-1}\right.$ ] was determined using $\mathrm{T}_{\mathrm{O}}=300^{\circ} \mathrm{K}$. The mean parent molecule desorption heats of $5200 \mathrm{cal}^{\mathrm{mol}}{ }^{-1}$ and 5900 cal. $\mathrm{mol}^{-1}$ for the predecessor of $\mathrm{CN}$ and $\mathrm{C}_{2}$, respectively, differ from each other They are larger than the value $4500 \mathrm{cal}^{\mathrm{mol}}{ }^{-1}$ which was found for $\mathrm{CN}$ and $\mathrm{C}_{2}$ in Comet Rudnicki (1966e) (Mayer,

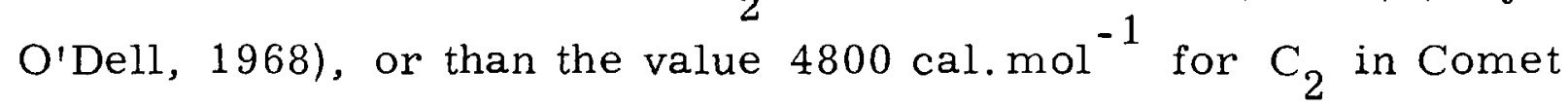
Arend-Roland (1957 III) (Liller, 1965) If we use $\alpha<05$ as recommended by some authors and still $\mathrm{T}_{\mathrm{o}}=300^{\circ} \mathrm{K}$, we would receive $B$ and $L$ even larger: e g $6400 \mathrm{cal}^{-\mathrm{mol}^{-1}}$ (CN) and 7300 cal. $\mathrm{mol}^{-1}\left(\mathrm{C}_{2}\right)$ for $\alpha=04$, or $8500 \mathrm{cal} . \mathrm{mol}^{-1}(\mathrm{CN})$ and 9600 cal. $\mathrm{mol}^{-1}\left(\mathrm{C}_{2}\right)$ for $\alpha=03$ For that reason it seems to be more justified to accept $\quad \alpha=05$ for Comet 1973f, assuming again $\mathrm{T}_{\mathrm{O}}$ as given above

Following the method introduced by Wurm (1943) the number of molecules $\mathrm{CN}$ or $\mathrm{C}_{2}$ in the cometary head can be calculated from the respective luminosities $L$ :

$$
N=L \frac{m_{e}}{\pi e^{2} f p \rho(v, r)}
$$

where $f$ is the oscillator strength, $p$ is the vibrational transition probability and $\rho(v, r)$ is the solar radiation density at the given frequency and for the given heliocentric distance. We used the 
molecular constants presented in Table 6 (for $f$ see Wentink et al., 1964; for $p$ see Fraser et al., 1954) and $\rho(v, r)$ resulting from the solar spectral irradiance data listed by Robinson (1966). The absolute luminosities appearing in Table 5 were calculated from the corresponding fluxes. $\mathrm{L}_{\mathrm{O}}=4 \pi \Delta^{2} \mathrm{~F}_{\mathrm{O}}^{\prime}=2812 \times 10^{27} \mathrm{~F}_{\mathrm{O}}^{\prime}$ $\left(\Delta=1\right.$ A.U.) Then, the number of molecules $C N$ and $C_{2}$ which radiated in the cylinders extending through the comet in the line of sight and of diameters $D\left(40^{\prime \prime}\right)$ and $D\left(80^{\prime \prime}\right)$ were determined (Table 6)

The ratio $\mathrm{N}_{\mathrm{o}}\left(\mathrm{C}_{2} 5165\right) / \mathrm{N}_{\mathrm{o}}(\mathrm{CN})=152$ or 146 , and $\mathrm{N}_{\mathrm{o}}\left(\mathrm{C}_{2} 4737\right) /$ $\mathrm{N}_{\mathrm{o}}(\mathrm{CN})=0.99$ or 0.88 for the $40^{\prime \prime}$ and $80^{\prime \prime}$ diaphragms is very low and comparable with the value 08 obtained for Comet Burnham (1960 II) by Arpigny (1965). Also Vanýsek (1969) found for Comet Ikeya-Seki (1968 I) a rather low value of $\mathrm{N}\left(\mathrm{C}_{2}\right) / \mathrm{N}(\mathrm{CN})=32$. It is interesting to notice that $1960 \mathrm{II}$ as well as $1973 \mathrm{f}$ are very probably "new" comets and that the orbital eccentricity of 1968 I was also very high (0.99915)

There exi sts a discrepancy between $\mathrm{N}_{2}\left(\mathrm{C}_{2}\right)$ as derived from the $\lambda 4737$ and $\lambda 5165$ bands: $N_{0}\left(C_{2} 5165\right) / N_{0}\left(C_{2} 4737\right) \simeq 16$ An even larger difference in $\mathrm{N}\left(\mathrm{C}_{2}\right)$ was already found for Comet Ikeya (1964f) by Kovar and Kovar (1965)

\section{Conclusions}

Summarizing our results based on the photoelectric observations of Comet 1973 f we may conclude.

After the perihelion passage the comet's luminosity was quickly diminishing partly due to declining ejection of both gas molecules and dust particles from the nucleus. The respective photometric parameters are given in Tables 2 and 5 . Measurements in two 


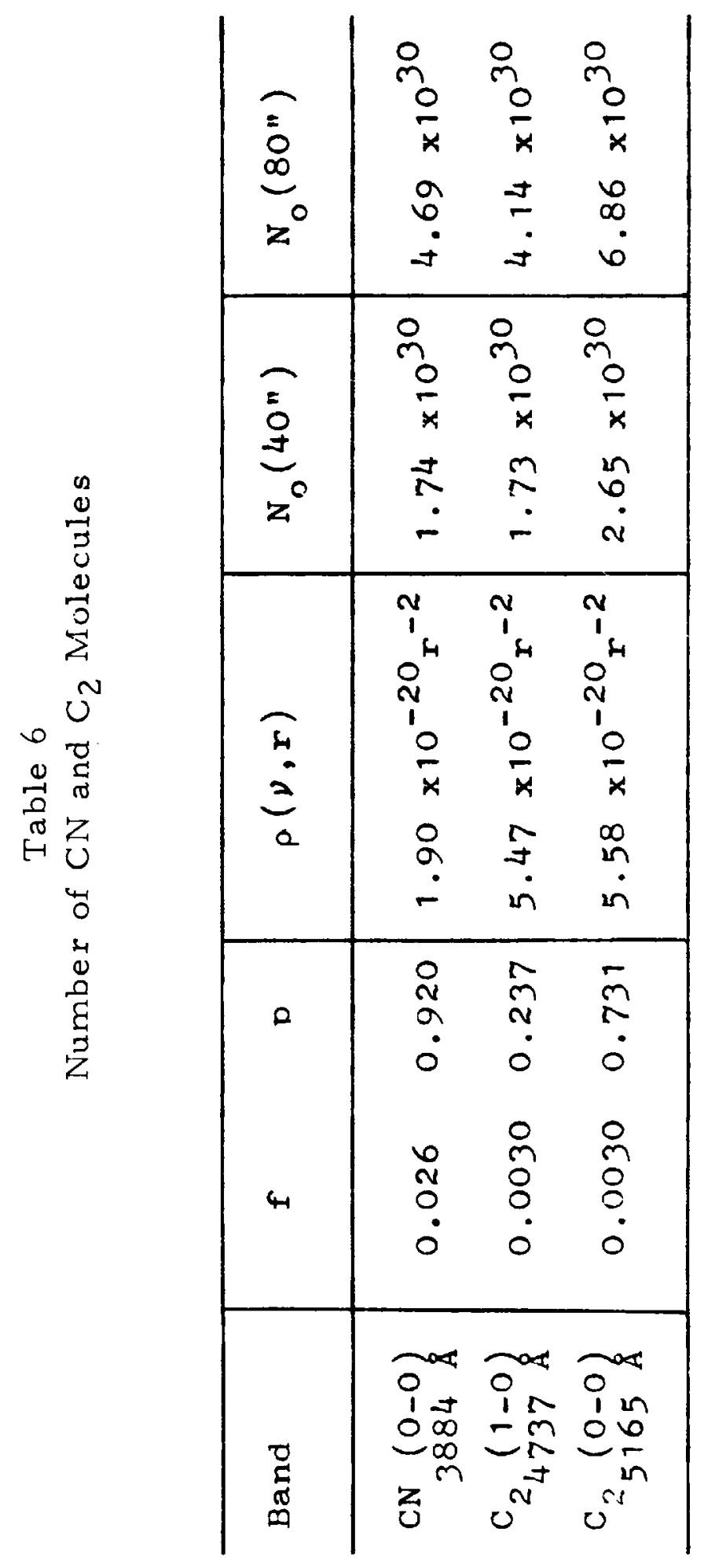


diaphragms, $40^{\prime \prime}$ and $80^{\prime \prime}$ in diameter, indicate the deviation from the intensity law $\rho^{-1}$ for a spherically-symmetric coma and agree with the $\rho^{-\mathcal{H}}$-law; $\mathcal{H}$ decreases with increasing heliocentric distance, the mean $\mathcal{H}$ values lie between 075 and 0.91 The dust constituent of the coma was medium intense ( $k$ between 0.6 and 1 1), and the dust particles were probably of larger size because of the nearly pure reflecting cometary continuum The desorption heats for $\mathrm{CN}$ and $\mathrm{C}_{2}$ parent molecules were unequal (5200 and $\left.5900 \mathrm{cal}^{-1} \mathrm{~mol}^{-1}\right)$ and somewhat higher compared with former results The ratio $\mathrm{N}_{\mathrm{o}}\left(\mathrm{C}_{2}\right) / \mathrm{N}_{\mathrm{o}}(\mathrm{CN})$ was very low $(09$ to 1 5) and slightly depending on the choice of the $\mathrm{C}_{2}$ emission band. Assuming $\mathrm{T}_{\mathrm{O}}=300^{\circ} \mathrm{K}$, the constant $\alpha=05$ has been accepted which corresponds to the equilibrium state of the nucleus

\section{Acknowledgments}

I wish to thank Mr G Senkbeil for carrying out part of the observations at La Silla, Mr T Kleine, B. Loibl, J Prölß and R Wehmeyer for their assistance with the reduction, and Professor V Vanýsek and Dr.J Rahe for valuable comments on this paper I am grateful to the ESO directorate for providing me with observing time at the $50 \mathrm{~cm}$ telescope and to the Stiftung Volkswagenwerk for a grant which supported this work. 


\title{
References
}

\begin{abstract}
Allen C W , 1973, Astrophysical Quantities, Third Ed., The Athlone Press

Arpigny C , 1965, Mem. Acad.Roy. Belgique, Vol.35, part $5=$ Liège Contr No. 493

Blanco V M , Demers S., Douglass G G., Fitzgerald M P , 1968, Photoelectric Catalogue, Publ. Naval Obs., Second Series, Vol.XXI.
\end{abstract}

Fraser P A., Jarmain W R, Nicholls R.W, 1954, ApJ 119, 286

Hayes D.S., 1970, ApJ 159, 165.

Kohoutek L , Rahe J , 1974, this colloquium

Kovar N A., Kovar R P , 1965, ApJ 142, 1191

Levin B.J , 1943, AJ USSR 20, 37; 1948, AJ USSR 25, 246.

Liller W , 1965, Nature et origine des comètes (Rept.13th Liège Symp.), 195.

Mayer P., O'Dell C R, 1968, ApJ 153, 951.

Robinson N , 1966, Solar Radiation, Elsevier Publ. Comp. Amsterdam/London/New York, p. 2

Vanýsek V , 1969, BAC 20, 355.

Vogt N , 1974, I.A. U Circ. No.2631

Wentink T Jr, Davis J, Isaacson L, Spindler R, 1964, Electronic Oscillator Strengths of Diatomic Molecules, AVCO, RAD-TM-64-63, July 29

Wurm K., 1943, Mitt. Hamburger Sternwarte Vol.8, No.51 